\title{
ENFRENTAMENTO À POBREZA NO BRASIL: programas de transferência de renda e particularidade do Programa Bolsa Família
}

\section{Facing poverty in Brazil: income transfer programs and particularity of the Bolsa Família Program}

\author{
Francisco Rafael de Castro Chaves ${ }^{1}$ \\ Yashmin Michelle Ribeiro de Araujo $^{2}$ \\ Cristiane Maria Marinho ${ }^{3}$
}

\begin{abstract}
RESUMO: A pobreza é uma expressão da "questão social" com raízes gestadas na relação existente entre o capital e o trabalho. Sua ampliação dentro do modo de produção capitalista demarca a opção deste por não superá-la, mas sim garantir sua manutenção ou redução estratégica através do investimento em políticas públicas. No caso brasileiro, o enfrentamento à pobreza tem se dado, entre outras formas, com os programas de transferência de renda, que garantem mínimos sociais aos beneficiários. Entre eles, desde os anos 2000, o Programa Bolsa Família tem ganhado relevância e visibilidade entre os indivíduos e famílias incluídos nos critérios exigidos para o seu acesso. Sendo assim, este trabalho propõe, através de pesquisa bibliográfica e documental, refletir sobre a articulação existente entre o enfrentamento à pobreza em nosso país e os programas de transferência de renda, particularmente, o Programa Bolsa Família. A investigação desenvolvida nos permite concluir pela importância do Programa Bolsa Família, como um programa de transferência de renda, para o enfrentamento à pobreza em nosso país a partir do acesso aos mínimos sociais, porém nos exige ressaltar sobre as limitações na sua operacionalização e os desafios postos para a minimização da desigualdade social numa sociedade como a brasileira, marcada pela injusta distribuição da riqueza socialmente produzida.
\end{abstract}

Palavras-chaves: Pobreza. Programa Bolsa Família. Programas de Transferência de Renda.

ABSTRACT: Poverty is an expression of the "social question" with roots rooted in the relationship between capital and labor. Its expansion within the capitalist mode of

\footnotetext{
${ }^{1}$ Graduando do curso de Serviço Social (Universidade Estadual do Ceará - UECE). Bolsista no Programa de Monitoria Acadêmica (PROMAC-PROGRAD) na disciplina de Direito e Legislação Social. Pesquisador do Laboratório de Estudos e Pesquisas em Afrobrasilidades, Gênero e Família (NUAFRO). E-mail: francisco.chaves@aluno.uece.br.

2 Professora do curso de Serviço Social (UECE); Graduada em Serviço Social (UECE); Especialista em Serviço Social, Política Social e Seguridade Social (Faculdade Ratio/Pótere Social); Mestra em Serviço Social, Trabalho e Questão Social (MASS-UECE). Pesquisadora do Laboratório de Pesquisas e Estudos em Serviço Social (LAPESS). E-mail: yashminmichelle@yahoo.com.br.

${ }^{3}$ Professora de Filosofia do Mestrado Acadêmico em Serviço Social (MASS-UECE); Especialista em Economia Política (UECE); Mestra em Filosofia (UFPB/UFMG); Doutora em Educação (UFC); Pósdoutora em Filosofia da Educação (UNICAMP); Doutoranda em Filosofia (UFG). E-mail: cmarinho2004@gmail.com.
} 
production demarcates the latter's option not to overcome it, but rather to guarantee its maintenance or strategic reduction through investment in public policies. In the Brazilian case, the fight against poverty has occurred, among other forms, with income transfer programs, which guarantee social minimums for the beneficiaries. Among them, since the 2000s, the Bolsa Família Program has gained relevance and visibility among individuals and families included in the criteria required for their access. Therefore, this paper proposes, through bibliographical and documentary research, to reflect on the articulation existing between the confrontation with poverty in our country and the income transfer programs, particularly the Bolsa Família Program. The research developed allows us to conclude on the importance of the Bolsa Família Program, as a income transfer program, to address poverty in our country from access to social minimums, but it requires us to highlight the limitations in its operationalization and the challenges to minimize social inequality in a society such as Brazil, marked by the unfair distribution of socially produced wealth.

Key-words: Poverty. Bolsa Família Program. Income Transfer Programs.

\section{INTRODUÇÃO}

A pobreza, em sua forma relativa ou absoluta, vem colocando-se no contexto atual, como uma expressão da "questão social" que se amplifica em decorrência da relação cada vez mais exploratória do capital em sua fase monopólico-financeira (YAZBEK, 2012). Sua ampliação neste modo de produção demarca a opção capitalista pela manutenção deste modo de produção, dos superlucros e da exploração do trabalho humano. Assim, o capital mundializado avança na produção de recursos tecnológicos, ao mesmo tempo em que regride no amparo às condições de vida e laborais dos trabalhadores (SILVA, 2011), provocando cada vez mais a expansão das expressões da "questão social", onde se inclui a pobreza.

Se o pauperismo, vindo à lume, no momento da industrialização inglesa, no primeiro terço do século XIX, mostrava-se como um fenômeno novo por existir quando precisamente 0 desenvolvimento das forças produtivas permitia sua supressão (PAULO NETTO, 2001, p. 153-154), hoje, este ainda preserva sua razão comum: a relação capital versus trabalho. Esta se particulariza pelas feições regionais, locais ou nacionais dos diferentes países que, muitas vezes, podem suprimir o avanço dos limites da pobreza, mas não o fazem pelo compromisso aos ditames do capital. 
Vale ressaltar que a pobreza deve ser pensada como uma insuficiência não apenas financeira, mas também de autonomia, de liberdade e segurança para a participação na vida pública, de exercício da cidadania, entre outros aspectos (REGO; PINZANI, 2014; SILVA, 2007). No caso brasileiro, o tratamento dado a ela tem demonstrado sua associação com a Política Nacional de Assistência Social (PNAS), responsável por efetivar a "assistência social como direito de cidadania e responsabilidade do Estado" (BRASIL, 2005, p. 13), tendo como público alvo, os indivíduos e as famílias que se encontram "em situações de vulnerabilidade e risco social", como a "exclusão pela pobreza" (BRASIL, 2005, p. 33).

A partir destas discussões, este trabalho se justifica pela relevância em se debater sobre a pobreza, fortemente relacionada à desigualdade social, característica de nosso país, e o modo como o Estado vem lidando com o enfrentamento desta, isto é, por meio dos programas de transferência de renda, entre os quais, o Programa Bolsa Família (PBF). Com base nisso, através de pesquisa bibliográfica e documental, propomo-nos a refletir, ao longo deste texto, sobre a articulação existente entre o enfrentamento à pobreza em nosso país e os programas de transferência de renda, particularmente, o PBF.

Para tanto, dividimos nossa exposição em dois tópicos centrais, que seguem esta introdução. No primeiro, debateremos sobre as diferentes percepções em torno do que seja a pobreza, demonstrando sua materialização como expressão da "questão social" que supera a falta de recursos financeiros. Além disso, apresentaremos a PNAS como a política pública responsável pelo amparo às pessoas que se encontram em situação de pobreza e outras expressões da vulnerabilidade e do risco pessoal e social. Em seguida, discutiremos a respeito dos programas de renda mínima e o modo como as políticas públicas vêm se traduzindo na contemporaneidade; os programas de transferência de renda, elucidando as visões divergentes sobre o que são; e, a posteriori, apresentaremos o PBF como um dos programas de transferência de renda de maior abrangência no Brasil, visualizado como um importante instrumento para o enfrentamento à pobreza.

\section{ELEMENTOS PARA PENSAR O DEBATE EM TORNO DA POBREZA}

O surgimento dos programas de renda mínima no Brasil está atrelado ao contexto econômico mundial, marcado pelas transformações ocorridas no mundo do 
trabalho a partir dos anos 1970, devido à crise estrutural do capital, que responde com a reestruturação produtiva, novas formas de acumulação (flexíveis) e o neoliberalismo (ANTUNES, 2009). As consequências destas transformações se expressam, entre outras coisas, na precarização e fragmentação do trabalho, no desemprego e nos índices elevados de pobreza: consequências profundamente entrelaçadas.

A respeito disso, cabe dizer que existem diferentes concepções sobre a pobreza, orientadas por valores definidores da construção e da implementação de diversas alternativas de políticas de intervenção social (SILVA, 2007). Com efeito, a pobreza apresenta dimensões histórica, econômica, social, cultural e política. Ela é complexa, multidimensional e tem natureza estrutural, sendo, portanto, mais que insuficiência de renda. Partindo desta prerrogativa, ela é produto da exploração do trabalho; é desigualdade na distribuição da riqueza socialmente produzida; é não acesso aos serviços sociais básicos, à informação, ao trabalho e à renda digna; é não participação social e política (SILVA, 2007, p. 1430). Sendo assim, em nossa percepção, a pobreza é entendida como uma expressão da "questão social", pois revela, conforme mencionamos, a desigualdade, a exploração do trabalho, ao mesmo tempo em que as lutas sociais em favor da alteração destas condições de injustiça social.

Yazbek (2012) conceitua pobreza como uma das manifestações da "questão social" por afirmar que esta é uma expressão direta do desenvolvimento capitalista gerador de desigualdades e miséria. Para ela, os pobres são produto das relações que produzem e reproduzem a desigualdade no plano social, político, econômico e cultural, definindo um lugar subalterno para eles na sociedade. Neste são desqualificados por suas crenças, seu modo de expressarem-se e seu comportamento social, considerados sinais de "qualidades negativas" que lhes são conferidas por sua procedência de classe (sua condição social). Este lugar tem contornos ligados à própria trama social que gera a desigualdade - onde se incluem devido à situação de pobreza - e que se expressa não apenas em circunstâncias econômicas, sociais e políticas, mas também nos valores culturais das classes subalternas e de seus interlocutores na vida social (YAZBEK, 2012, p. 289-290).

\footnotetext{
${ }^{4}$ A questão social "condensa o conjunto das desigualdades e lutas sociais, produzidas e reproduzidas no movimento contraditório das relações sociais, alcançando plenitude de suas expressões e matrizes em tempo de capital fetiche" (IAMAMOTO, 2010, p.156).
} 
Rego e Pinzani (2014) contribuem para esta discussão defendendo que a pobreza não deve ser considerada a partir de uma perspectiva somente econômica, que considere exclusivamente a falta ou insuficiência de renda, embora o aspecto econômico ligado a uma renda regular ainda se constitua como uma condição para a saída da miséria. A pobreza deve ser compreendida, na verdade, como privação de "capabilities básicas" em lugar do mero baixo nível de renda, que é o critério mais comum para a identificação da pobreza. "Todavia, a baixa renda é uma das causas principais da pobreza, pois a falta de renda pode ser uma razão primordial da privação de capabilities" (SEN, 2000 apud REGO; PINZANI, 2014, p.156).

Assim, é necessário considerarmos tanto a falta ou insuficiência de renda, como também o autorrespeito e à autonomização dos indivíduos para caracterizar o que seja a pobreza. Isto significa dizer que entre os aspectos econômicos e éticos que configuram a pobreza, destacam-se: a falta de condições básicas para uma vida saudável, o trabalho infantil e o abandono escolar, a alta natalidade, os acidentes, a falta de crédito, a invisibilidade e a mudez diante da participação política e social, a desigualdade interna às famílias, a vergonha, a cultura da resignação e a exclusão de cidadania (REGO; PINZANI, 2014).

A Política Nacional de Assistência Social (PNAS), visando agir sobre os elementos que configuram a pobreza, objetiva efetivar a assistência social como direito e responsabilidade do Estado. Desse modo, adota as dimensões da proteção social básica e da proteção social especial (de média complexidade e alta complexidade), isto é, as proteções afiançadas à referida política. A primeira delas busca trabalhar com famílias a fim de potencializar os vínculos familiares e comunitários, isto é, atua no âmbito da "prevenção de situações de risco através do desenvolvimento de potencialidades e aquisições" e o "fortalecimento de vínculos familiares e comunitários", tendo "caráter preventivo" e visando "à inclusão social" (BRASIL, 2005, p.33).

A segunda é orientada às famílias e aos indivíduos que vivenciam alguma situação de risco pessoal e social, tais como: o abuso sexual, o abandono ou o trabalho infantil. Dentro desta, a modalidade da proteção social especial de média complexidade é aquela destinada aos indivíduos e famílias incluídos na situação mencionada, com direitos violados, mas que ainda tenham vínculos familiares e comunitários vigentes. A modalidade da proteção social especial de alta complexidade, por sua vez, é dirigida aos que se encontram "sem referência e, ou, 
em situação de ameaça, necessitando ser retirados de seu núcleo familiar e, ou, comunitário" (BRASIL, 2005, p.34).

É preciso esclarecer que a assistência social como política pública não é a única existente para o enfrentamento à pobreza em nosso país, embora ela opere com maior frequência junto à população com menos condições de sobrevivência (SPOSATI, 2007). Vale ressaltar que a pobreza e "o estatuto de pobre" dirigido aos indivíduos que usufruem da política de assistência social e/ou frequentam os CRAS ${ }^{5}$ "[...] resulta de um modelo sócio-econômico estrutural e nenhuma política social tem resolutividade sobre ele. Resolver pobreza supõe redistribuição em salários, meios, acessos, representação, participação" (SPOSATI, 2007, p. 19). Ou seja, supõe a supressão da desigualdade social e a distribuição da riqueza socialmente produzida, elementos profundamente relacionados ao modo de produção exploratório capitalista, que se mantém com base nesta mesma desigualdade e na não distribuição da riqueza produzida visando alcançar superlucros.

O Sistema Único de Assistência Social (SUAS) aprovado em 2005 pelo Conselho Nacional de Assistência Social através da Norma Operacional Básica (NOB) no 130 apresenta a assistência social como política pública de direito, sendo importante dentro do debate sobre a pobreza, porque materializa a Lei Orgânica da Assistência Social (LOAS), bem como auxilia na descentralização políticoadministrativa da assistência nos territórios (BRASIL, 2005). Ele torna a política de assistência social mais acessível aos usuários, criando maneiras de participação da sociedade civil e do Estado, contribuindo, portanto, no processo de enfrentamento da pobreza.

Para a construção desta política de âmbito nacional, tivemos a promulgação da Constituição Federal de 1988, um marco regulatório da democracia e da cidadania em nosso país. Posteriormente, a aprovação da LOAS, em 1993; a construção da PNAS, em 2004; e, por fim, o SUAS, em 2005, representando a afirmação da política de assistência social como política pública, direcionada aos segmentos carentes de renda, condições dignas de vida e acesso aos serviços básicos inerentes à vida humana. Percebemos, desse modo, que a política de assistência social traz importantes avanços para a construção de uma sociedade com menos pobreza no Brasil, apesar de sabermos que suas ações apenas

\footnotetext{
${ }^{5}$ Porta de entrada da proteção social básica (BRASIL, 2005).
}

Cadernos Cajuína, V. 4, N. 2, 2019, p.95 - 109. 
contribuem para uma redução da pobreza, através dos programas, projetos e serviços operacionalizados a partir da assistência social, como são os programas de transferência de renda.

Cabe sinalizar para este fato, pois é lúcido esclarecer, como afirmamos anteriormente, que compreendemos a pobreza como uma expressão da "questão social” e, sendo assim, ela é necessária para a manutenção do modo de produção capitalista. Na realidade, "o desenvolvimento capitalista produz, compulsoriamente, a 'questão social'” (PAULO NETTO, 2001, p. 157, grifos do autor), e a pobreza como expressão desta, consequentemente, atualiza-se neste modo de produção. Abordaremos a respeito do enfrentamento da pobreza no Brasil a partir dos programas de transferência de renda e, particularmente, do PBF, no tópico seguinte.

\section{3. tRANSFERÊnCIA DE RENDA, PROGRAMA BOLSA FAMílIa E ENFRENTAMENTO À POBREZA NO BRASIL}

A discussão sobre renda mínima embora ainda restrita ganhou destaque no cenário brasileiro a partir dos anos 1990, com a aprovação no Senado Federal de uma lei de autoria do senador petista Eduardo Suplicy, que propunha a instituição do Programa de Garantia de Renda Mínima (SUPLICY; NETO, 1995). A renda mínima "é entendida como uma transferência monetária a indivíduos ou a famílias [...], complementando ou substituindo outros programas sociais, objetivando garantir um patamar mínimo de satisfação de necessidades básicas" (SILVA, 1997, p. 16).

O Programa de Garantia de Renda Mínima adquiriu maior expressão nos municípios brasileiros especificamente a partir de 1994, primeiramente nos municípios da região sudeste e centro-oeste, pois estes passaram a adotar programas do tipo "renda mínima" (SILVA, 1997). A municipalização da discussão sobre renda mínima fez nascer, assim, o debate sobre a descentralização dos programas alternativos que objetivam atenuar o aumento da pobreza no Brasil, ampliada por conta da crise econômica de 1980 e 1990 e pela instauração do projeto neoliberal no país (SILVA, 1997).

Neste sentido, cabe assinalar a diferença entre os conceitos de mínimos sociais e necessidades básicas. 
Enquanto o mínimo pressupõe supressão e cortes do atendimento, tal como propõe a ideologia liberal, o básico requer investimentos sociais de qualidade para preparar o terreno a partir do qual maiores atendimentos podem ser prestados e otimizados. Em outros termos, enquanto o mínimo nega o 'ótimo' de atendimento, o básico é a mola mestra que impulsiona a satisfação básica de necessidades em direção ao ótimo (PEREIRA, 2011, p. 26, grifos do autor).

Mínimos sociais e necessidades básicas se colocam, portanto, na complexidade que subentende o modo como as políticas públicas vêm se materializando na contemporaneidade, mais especificamente no capitalismo neoliberal. Isto porque esta face do capitalismo pressupõe políticas públicas menos universais, mais focalizadas, marcadas pela precarização e pela exigência de contrapartida por parte dos beneficiários (YAZBEK, 2016, p. 6-7), demonstrando uma prevalência de políticas que garantem o mínimo (do mínimo) e não as necessidades básicas dos sujeitos.

Além disso, os sistemas de proteção social universais foram desconstruídos, ampliando-se, em seu lugar, o Estado que "ampara os mais pobres" em decorrência da precarização do emprego e das condições de trabalho, que ocasionam a dificuldade de sobrevivência unicamente pelo resultado do trabalho ou a dificuldade de acesso ao direito ao trabalho em condições minimamente adequadas. Assim, "as classes trabalhadoras, mesmo ampliando a radicalização de sua exploração transformam-se nos pobres no âmbito das Políticas Sociais" (YAZBEK, 2016, p. 8). Este mesmo Estado é aliado de instituições multilaterais que despolitizam a pobreza em articulação com a relação capital/trabalho, contribuindo para que os fatores estruturais causadores desta sejam obscurecidos e os pobres sejam responsabilizados por sua situação (YAZBEK, 2016, p. 7-8).

Dessa forma, os programas de transferência de renda, elaborados com base na focalização e na exigência de condicionalidades, contribuem para a ampliação de mercados através de relações fundamentadas na transferência de recurso monetário para a garantia de condições mínimas de sobrevivência e a participação na economia, nos momentos de crise do capital (YAZBEK, 2016, p. 6-8). Jaccoud (2007) recorda que no conjunto dos benefícios monetários operados pelo governo federal, destacam-se: o Benefício de Prestação Continuada (BPC), a Previdência Social e o Programa Bolsa Família (PBF). Todos estes são mecanismos de enfrentamento à 
pobreza que apresentaram no Brasil, nos últimos anos, aspectos positivos na redução desta.

Nesta discussão, vale dizer que os programas de transferência de renda brasileiros são compreendidos sob diferentes perspectivas. Há quem os entenda como sendo de "caráter compensatório" no enfrentamento à pobreza por serem materializados para substituírem o investimento em serviços sociais permanentes e eficazes. Outros os consideram como estratégias de "redistribuição de riqueza socialmente produzida", funcionando como um complemento aos serviços sociais direcionados à inclusão social. Por último, há os que encaram os programas de transferência de renda como estratégias provisórias para a inclusão dos sujeitos que estejam em situação de pobreza e/ou desemprego no universo laboral e social (SILVA; BARROS, 2007, p. 2).

Silva e Barros (2007, p. 3), de modo particular, entendem que os programas de transferência de renda compõem o sistema de proteção social brasileiro e, para tanto, a transferência monetária é um recurso utilizado para que os sujeitos que a usufruem possam acessar políticas sociais estruturantes, como educação e saúde. Ainda, estes programas se iniciariam a partir de um caráter compensatório, fornecendo os subsídios mínimos e urgentes de sobrevivência, adquirindo, a posteriori, um caráter de facilitadores para a autonomia dos seus beneficiários.

Dentre estes programas, o PBF, criado nos anos 2000, com o objetivo de unificar os programas de transferência de renda, teve grande relevância em todo o país, pois se colocou como um instrumento importante para "amenizar e dar acesso a milhares de cidadãos brasileiros às condições mínimas de sobrevivência" (SILVA; BARROS, 2007, p. 2), contribuindo com o combate à fome e à pobreza em nosso país. Entendemos que o PBF está situado dentro da proteção social básica, conforme dispõe a Política Nacional de Assistência Social (2004), uma vez que está voltado à prevenção de situações de risco através do desenvolvimento de potencialidades e aquisições e o fortalecimento de vínculos familiares, tendo caráter preventivo e de inclusão social.

O PBF é regulamentado pela Lei no 10.836, de 9 de janeiro de 2004, sancionada pelo presidente Luis Inácio Lula da Silva. Este programa tem como finalidade a unificação dos procedimentos de gestão e execução das ações de transferência de renda do governo federal, especialmente no que se referia ao Programa Nacional de Renda Mínima, vinculado à educação (Bolsa Escola), 
instituído pela Lei oㅜ 10.219, de 11 de abril de 2001; ao Programa Nacional de Acesso à Alimentação (PNAA), criado pela Lei oㅜ 10.689, de 13 de junho de 2003; ao Programa Nacional de Renda Mínima vinculada à Saúde (Bolsa Alimentação), instituído pela Medida Provisória oㅡ 2.206-1, de 6 de setembro de 2001; ao Programa Auxílio-Gás, instituído pelo Decreto o 4.102, de 24 de janeiro de 2002, e ao Cadastramento Único do Governo Federal, instituído pelo Decreto no 3.877, de 24 de julho de 2001 (BRASIL, 2004).

Cabe ressaltar que o PBF propõe como unidade beneficiária o grupo familiar, tendo a figura materna como representante preferencial. No entanto, a inclusão das famílias neste exige o cumprimento de algumas condicionalidades (como é natural às políticas públicas no contexto neoliberal), além do cumprimento dos critérios determinados para o seu acesso, entre os quais está o de renda, que demarca a vivência em condições sócio-econômicas marcadas pela pobreza e a extrema pobreza $^{6}$. As condicionalidades, por seu turno, são compromissos firmados entre a população beneficiária e o poder público, ajudando a criar uma espécie de responsabilidade mútua entre estes sujeitos. Esta responsabilidade se dá no sentido de que as famílias beneficiárias utilizem os serviços de saúde e educação e o poder público monitore e observe se estes serviços estão sendo ofertados e acessados da melhor forma possível (BRASIL, 2018, p. 69).

As condicionalidades incluem acompanhar o calendário de vacinas, o crescimento e o desenvolvimento (peso e altura) das crianças menores de 7 anos da família; realizar pré-natal (quando gestante); matricular e ter todas as crianças e adolescentes entre 6 e 15 anos da família com frequência escolar mensal mínima de 85\%; matricular e ter adolescentes de 16 e 17 anos da família, que sejam beneficiários do Benefício Variável Jovem (BVJ) com frequência escolar mensal mínima de 75\% (BRASIL, 2018, p. 70).

Desse modo, o PBF compreende o campo da assistência social e almeja:

(i) ser um benefício não contributivo; (ii) operar no âmbito da segurança de renda; e (iii) ter cobertura universal no grupo beneficiário. Se de fato o PBF não pode ser identificado a um direito

\footnotetext{
6 "O Bolsa Família é um programa de transferência direta de renda direcionado às famílias em situação de pobreza (renda per capita mensal entre $R \$ 85,01$ e $R \$ 170,00$ ) e de extrema pobreza (renda per capita mensal de até $\mathrm{R} \$ 85,00$ ). Ao entrarem no programa, os beneficiários recebem o dinheiro mensalmente e, como contrapartida, cumprem compromissos nas áreas de saúde e educação". Disponível em: <http://mds.gov.br/area-de-imprensa/noticias/2018/fevereiro/beneficiariosdo-bolsa-familia-aprovam-agilidade-na-concessao-do-pagamento>. Acesso em: 10 dez. 2018.
} 
social, sua criação, entretanto, significou um alargamento expressivo na seguridade social brasileira no campo da segurança de renda (JACCOUD, 2007, p. 31).

Podemos dizer que o PBF colabora com a segurança de renda às famílias em situação de pobreza, garantindo-Ihes os mínimos sociais para a sobrevivência. Ele é concebido como expressão do processo de desenvolvimento desses programas apresentados e a transferência de renda é entendida como uma transferência monetária direta efetuada a estes indivíduos ou às suas famílias (SILVA, 2007). Logo, com o PBF,

[...] o pressuposto central é de articular uma transferência de renda com políticas e programas estruturantes, principalmente no campo da educação, saúde e trabalho, direcionados a famílias pobres, pode interromper o ciclo vicioso da pobreza do presente e sua reprodução no futuro. Portanto, uma articulação entre uma transferência monetária com políticas e programas estruturantes, direcionados a famílias pobres, pode possibilitar a construção de uma política de enfrentamento à desigualdade social (SILVA, 2007, p. 1429).

Isto elucida que a transferência de renda aparece como um passo inicial em direção à construção de uma política de enfrentamento à desigualdade social. Contudo, não podemos esquecer de que dentro do modo de produção capitalista, a pobreza e outras expressões da "questão social", reveladoras do conjunto das desigualdades sociais, jamais serão suprimidas por completo, tendo em vista a própria razão de ser do capitalismo, o que não significa dizer que não existam resistências sendo gestadas e modificando, pouco a pouco, as condições postas na realidade social pelo capital (PAULO NETTO, 2001; IAMAMOTO, 2010), como demonstram os programas, projetos e serviços do âmbito da política de assistência social, por exemplo.

Na perspectiva de Rego e Pinzani (2014), a obtenção de uma renda básica condicionada, permanente e direcionada contribui para o desenvolvimento das potencialidades dos menos favorecidos em nosso país. Por isso, a política de transferência estatal de renda no Brasil atual não é simplesmente uma política de urgência moral que garante o direito à vida, mas sim representa o início da substantivação da nossa democracia. Isto porque, na história e em diversas situações nacionais, as urgências morais, quando reconhecidas como tais pelo 
Estado, deram início a processos democráticos mais profundos (REGO; PINZANI, 2014, p. 221).

Devemos ressaltar que o PBF, como um programa de transferência de renda, deve funcionar com o objetivo de gerar oportunidades para que as famílias em situação de pobreza e extrema pobreza consigam superar esta condição. No entanto, nosso país, ainda não tem conseguido contribuir efetivamente com o desenvolvimento das potencialidades desta população. Isto se deve principalmente ao fato de não termos oportunidades sendo construídas para os segmentos mais carentes, ocasionando que estes encontrem limitações para mobilizarem recursos sociais e econômicos visando superar a situação de pobreza e vulnerabilidade (JACCOUD, 2007). Assim, podemos compreender a importância do PBF para a garantia dos mínimos sociais através da transferência de renda, ao mesmo tempo em que vale ressaltar a precariedade na efetivação das propostas para a construção de potencialidades e de oportunidades para as famílias beneficiárias.

\section{CONCLUSÃO}

O caminho a percorrer para a garantia efetiva de condições dignas de vida que possibilitem aos segmentos pauperizados da nossa sociedade a superação da situação de vulnerabilidade e risco pessoal ou social ainda é longo, porém devemos ressaltar a relevância das políticas que visam à garantia dos mínimos sociais, principalmente a política de assistência social.

Os programas de transferência de renda relacionam-se a esta como instrumentos importantes, que vêm sendo utilizados pelo poder público brasileiro, para o enfrentamento à pobreza em nosso país. O PBF, de modo particular, foi criado para unificar outros programas de transferência de renda existentes, ganhando visibilidade e credibilidade junto à população beneficiária por sua contribuição para o acesso à renda por famílias e indivíduos em situação de pobreza e extrema pobreza. A partir deste acesso, outros direitos podem ser garantidos, tendo em vista a possibilidade de compra e venda de produtos e serviços no mercado.

É interessante dizer, todavia, que, no capitalismo neoliberal, em sua fase monopólico-financeira, as políticas públicas, onde se encontra a política de 
assistência social (que busca atuar sobre a pobreza), são marcadas pela focalização, precarização e exigência de condições para o seu acesso, impactando no modo como estas políticas se materializam. Sendo assim, o enfretamento à pobreza por meio dos programas de transferência de renda, como o PBF, pode se dar através da construção de potencialidades, da autonomia e de oportunidades para os segmentos pauperizados. Entretanto, esta construção ocorre com amplas limitações, prejudiciais à superação da situação de pobreza e vulnerabilidade.

Devemos também recordar que as políticas públicas no modo de produção capitalista não propõem a superação definitiva da pobreza e de outras expressões da "questão social", uma vez que estas expressões estão fortemente articuladas à força motora do capitalismo, já que gestadas pela relação de exploração originada no confronto entre capital e trabalho (PAULO NETTO, 2001; IAMAMOTO, 2010). Dito de outro modo: os programas de transferência de renda colaboram no enfrentamento à pobreza e podem funcionar como o primeiro passo em direção à elaboração de uma política de enfrentamento à desigualdade social, porém esta jamais será suprimida em sua completude no modo de produção capitalista. Isto porque, neste modo de produção, classes antagônicas dividem espaço na cena pública; capitalistas exploram e trabalhadores são explorados; capitalistas exploram e trabalhadores lutam por melhores condições de vida; capitalistas exploram e trabalhadores resistem...

Neste sentido, a classe trabalhadora passa a ser beneficiária dos programas de transferência de renda, o que assinala a importância destes para o enfrentamento à pobreza pela via do acesso aos mínimos sociais (YAZBEK, 2016). No entanto, não podemos esquecer das limitações práticas destes programas e dos desafios colocados aos segmentos pauperizados para o seu acesso, que incluem 0 cumprimento do critério de renda per capita mensal (restrito às famílias em situação de pobreza e extrema pobreza), as "condicionalidades", assim como os desvios de verbas e a escassez de recursos.

A luta em favor da redução e posterior superação da pobreza, assim como pela distribuição justa da riqueza socialmente produzida, minimizando a desigualdade social existente, devem ser prioridades de toda a classe trabalhadora. O enfrentamento à pobreza pela via dos programas de transferência de renda, com destaque para o PBF, mostra-se, portanto, como um recurso imprescindível e 
legítimo desta luta, materializando o sistema de proteção social brasileiro e a urgência de ações estatais para a população pauperizada de nosso país.

\section{REFERÊNCIAS}

ANTUNES, Ricardo. Os sentidos do trabalho: ensaio sobre a afirmação e a negação do trabalho. 6. ed. São Paulo: Boitempo Editorial, 2009.

BRASIL: Beneficiários do Bolsa Família aprovam agilidade na concessão do pagamento.

Disponível em: <http://mds.gov.br/area-de-

imprensa/noticias/2018/fevereiro/beneficiarios-do-bolsa-familia-aprovam-agilidadena-concessao-do-pagamento>. Acesso em: 10 dez. 2018.

BRASIL. Ministério do Desenvolvimento Social, Secretaria de Avaliação e Gestão da Informação, Secretaria Nacional de Renda de Cidadania. Manual do Pesquisador: Programa Bolsa Família. Brasília, DF: Ministério do Desenvolvimento Social, 2018. p. 69-78.

. Ministério do Desenvolvimento Social e Combate à Fome, Secretaria Nacional de Assistência Social. Política Nacional de Assistência Social (PNAS/2004). Norma Operacional básica (NOB/SUAS). Brasília: Ministério do Desenvolvimento Social e Combate à Fome, 2005.

. Lei n. 10.836, de 9 de janeiro de 2004. Cria o Programa Bolsa Família e dá outras providências. Diário Oficial da União, Brasília, DF, 12 jan, 2004. Seção 1, p. 1. Disponível em: <http://www2.camara.leg.br/legin/fed/lei/2004/lei-10836-9-janeiro2004-490604-norma-pl.html>. Acesso em: 10 dez. 2018.

. Lei n. 8.742, de 7 de dezembro de 1993, Diário Oficial da União, Brasília, DF, 8 dez. 1993. Seção 1, p. 18769. Disponível em: <http://www2.camara.leg.br/legin/fed/lei/1993/lei-8742-7-dezembro-1993-363163publicacaooriginal-1-pl.html>. Acesso em: 10 dez. 2018.

Federal,1988.

Constituição da República Federativa do Brasil. Brasília, DF: Senado

IAMAMOTO, Marilda Vilela. Serviço Social em tempo de capital fetiche: capital financeiro, trabalho e questão social. 4. ed. São Paulo: Cortez, 2010.

JACCOUD, Luciana. Garantia de renda na perspectiva dos direitos socioassistenciais. In: Conselho Nacional de Assistência Social, Ministério de Desenvolvimento e Combate à Fome. IV Conferência Nacional de Assistência Social. Brasília: Conselho Nacional de Assistência Social, 2007. p. 27-35.

PAULO NETTO, José. Capitalismo e monopolista e serviço social. 5. ed. São Paulo: Cortez, 2001. 
PEREIRA, Potyara A. P. Necessidades humanas: subsídios à crítica dos mínimos sociais. 6. ed. São Paulo: Cortez, 2011.

REGO, Walquiria Leão; PINZANI, Alessandro. Vozes do Bolsa Família: autonomia, dinheiro e cidadania. São Paulo: Unesp, 2014.

SPOSATI, Aldaíza. Proteção e desproteção social na perspectiva dos direitos socioassistenciais. In: Conselho Nacional de Assistência Social. Ministério do Desenvolvimento Social e Combate à Fome. VI Conferência Nacional de Assistência Social. Brasília, DF: Conselho Nacional de Assistência Social, 2007. p. 17-22.

SUPLICY, Eduardo Matarazzo; NETO, Bazileu Alves Margarido. Políticas sociais: o Programa Comunidade Solidária e o Programa de Garantia de Renda Mínima.

Planejamento e Políticas Públicas, n. 12, p. 39-61, jan/dez. 1995. Disponível em: <http://www.ipea.gov.br/ppp/index.php/PPP/article/view/140>. Acesso em: 26 abr. 2018.

SILVA, Lenir Mainardes da; BARROS, Solange de Moraes. Bolsa família: estratégia de enfrentamento à pobreza no Brasil. In: JORNADA INTERNACIONAL DE POLÍTICAS PÚBLICAS, 3., 2007, São Luís. Anais... São Luís: Universidade Federal do Maranhão, 2007. p. 1-8.

SILVA, Maria Ozanira da Silva e. O Bolsa Família: problematizando questões centrais na política de transferência de renda no Brasil. Ciência \& Saúde Coletiva, v. 12, n. 6, p 1429-1439, 2007. Disponível em:

<http://www.scielo.br/pdf/csc/v12n6/v12n6a04.pdf>. Acesso em: 10 dez. 2018.

Renda mínima e reestruturação produtiva. São Paulo: Cortez, 1997.

SILVA, Newton Ferreira da. Mundialização do capital e precarização do trabalho.

Aurora, v. 5, n. 9, dez. 2011.

YAZBEK, Maria Carmelita. O desafio da defesa das Políticas Públicas para o Serviço Social. Argumentum, Vitória, v. 8, n.1, p. 6-13, jan./abr. 2016.

. Pobreza no Brasil contemporâneo e formas de seu enfrentamento. Serv.

Soc. e Soc., São Paulo, v. 110, n. 9, p.288-322, abr. 2012. 